\title{
The Dependence of Human Development on the Degree of Public Interest
}

\begin{abstract}
Askerov Shahlar
Baku State University

This study examines the impact of public and personal interest on human development. For this end, a new criterion was proposed for this purpose. This criterion indicates how many times the performed path of work is more than the defective part. This criterion was called quality factor. It is found out correlation between the Human Development Index and quality factor. It is shown that, as the quality factor increases, the level of public interest increases, the level of individual interests decreases and prosperity increases. Democratic thinking replaces administrative thinking. The author believes that humanity is developing in the direction of public interest and the history of humanity is the history of public interest. In order to help human development, the education system should be re-established and the content of the curriculum should be renewed so that the level of personal interests of individuals decreases, but the level of interests of the community increases.

Keywords: criterion, quality factor, management, public and personal interest, thinking style, human development index, gross domestic product
\end{abstract}

\section{New Criterion}

Human development is in the center of attention of modern countries (Askerov 2017). Until 1990, Gross Domestic Product (GDP) per capita was used as a criterion for assessing development and prosperity. Since there are many countries where GDP is high per capita, but the level of education, as well as the standard of living is low, and the life expectancy is short, one can clearly conclude that this criterion is not universal and exhaustive. There was a need for a new criterion.

As a criterion was taken the ratio of the realized part of the work (physical or intellectual) (a) to unrealized part (h), as the sum of the performed (a) and the deficits parts (h) of work equal to unit, then you can write:

$$
\mathbf{a}+\mathbf{h}=\mathbf{1}
$$

The new criterion was called quality factor (K) (Asgarov 2004) and was defined by the following formula:

$$
\mathbf{K}=\mathbf{a} / \mathbf{h}=\mathbf{a} / \mathbf{1}-\mathbf{a}
$$

The $\mathbf{K}$ factor shows how match the performed part (a) of the work exceedes the deficiency part of the work (1-a). This criterion is an alternative for the relative performance (per cent) of activity. Depending on the application area, $\mathbf{K}$ has different meanings. For example, in pedagogy (knowledge assessment), $\mathbf{K}$ indicates the ratio of what we know, to what we don't know (Askerov 2004); in public relations it shows the ratio of public interest to personal interest (Askerov 2017).

Askerov Shahlar, Doctor of Physical and Mathematical Sciences, professor, Institute for Physical Problems, Baku State University, Azerbaijan; main research fields: Cathode Sputtering, Metal-Semiconduktor Contact, Philosophy of Education, Econophysica. 
$\mathbf{K}$ can also be interpreted as the ratio of public interest to personal interests:

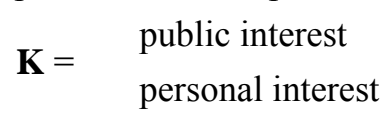

The individual interest is natural and starts at the moment of birth. All creatures have this feature. Public interest is generated later and it is derivative. This interest is connected with the emergence of consciousness. Public interest exists only in human societies. Public consciousness creates public interest.

As the social interest rises, the individual interest goes down and the value of $\mathrm{K}$ increases. The thinking becomes more maturity. Democratic thinking replaces administrative thinking.

Over the past three decades, the concept of human potential and human factor has been widely used (Askerov 2012): Thus, UNDP has been focusing on the development of human potential since 1990 (Proceeding UNDP, 2010).

International rankings of the states are based on the Human Development Index (HDI). As a global indicator, this index allows comparing states' development. Obviously, HDI is a time-dependent indicator.

The value of the HDI varies between zero and unit. For the countries that have a premium life expectancy, the index is more than 0.90 and for the low-income countries, the value is about 0.40 . Thus, the HDI reflects the targeted activity of a society. All humanity is moving towards a happy future. However, the successes of different countries in this process are different. According to the UNDP date for 2016 (Proceeding UNDP, 2016), Norway ranks first place, while Niger is in the last place. For Norway, HDI $=0.950$. This means that this state has fulfilled $95 \%$ of the Supreme Society building.

Obviously, there is no country on the planet with HDI $=1$ and will not be in the future, because the HDI approaches asymptotic in the unit. If $\mathbf{K} \rightarrow \infty$, then $\mathbf{a} \longrightarrow 1$. Given the heavenly books, it is possible to draw the conclusion that HDI $=1$ only for paradise, $\mathrm{HDI}=0$ for hell. It should be noted that it is impossible to establish a full democratic and high developed society with $\mathrm{K}=\infty$ (Askerov 2011).

According to the UNDP date (2016), the first three places are shared Norway, Australia, and Switzerland. The value of HDI varies them between $0.930-0.950$ for these countries. Therefore, these countries can be considered quasi-paradise countries.

Some of developing countries include Russia (0.798), Iran (0.766), Turkey (0.765), Georgia (0.754), and Azerbaijan (0.751), and so on. The HDI value for these countries varies from 0.751 to 0.798 . These small differences in HDI indicators create great differences in thought. For example, HDI for RF is 0.798 . Probably, this figure indicates that $79.8 \%$ of the Russian population has public interest, and $20.2 \%$ - personal interest. In contrast with developed countries, officials in these countries are elected by administrative methods within $20.2 \%$, rather than within $79.8 \%$ of the population.

For countries that share 185-188 places in the UNDP ranking (2016), the value of the HDI ranges from 0.348 to 0.392 . These countries are Chad (0.392), RSA (0.350), and Niger (0.348). Living conditions in these countries are very low. In these countries, the decisions are adopted by administrative methods.

HDI is an indicator of the relative achievement of states determined by the UNDP. However, if the HDI reflects the part of the work that the states has done, we can point HDI $=\mathbf{a}$.

The formula (2) allows you to create a new rating scale. By doing this, it is enough to set the dependence of a upon K. This dependency is shown in Fig. 1, where UNDP computed ranking of countries a (or HDI), which have drawn from new criterion $\mathbf{K}$. 
As seen from Fig. 1, the parameter a non-linear increases as the $\mathbf{K}$ factor increases (Askerov \& Askerov 2012). Besides, the welfare of society also increases together with the growing of $\mathbf{K}$. Thinking style becomes more pure, and more correct decisions are made. Conscious activity is growing. Public interest is more strictly protected. The increase of welfare depends on the increase of the public interest of the individual (or society), and the loss of personal interests. Based on these traits, such legality can be determined: in general, humanity, in particular society, is developing in the direction of growing public interest.

Governance is the key of increasing the power of states. Proper management can create great miracles. American management expert Gary Gamel (2007) believes that management is one of the great inventions (or methods) that unite people, mobilize their resources, and arrange production. The key issue in management is to make the right decision. The daily life of any country is making a lot of decisions. Some of these decisions can be democratic and some can be administrative. The election depends on human development, or rather the HDI's value. As the value of the maturity grows, the probability of making a democratic decision increases, and the likelihood of making totalitarian decisions decreases.

a

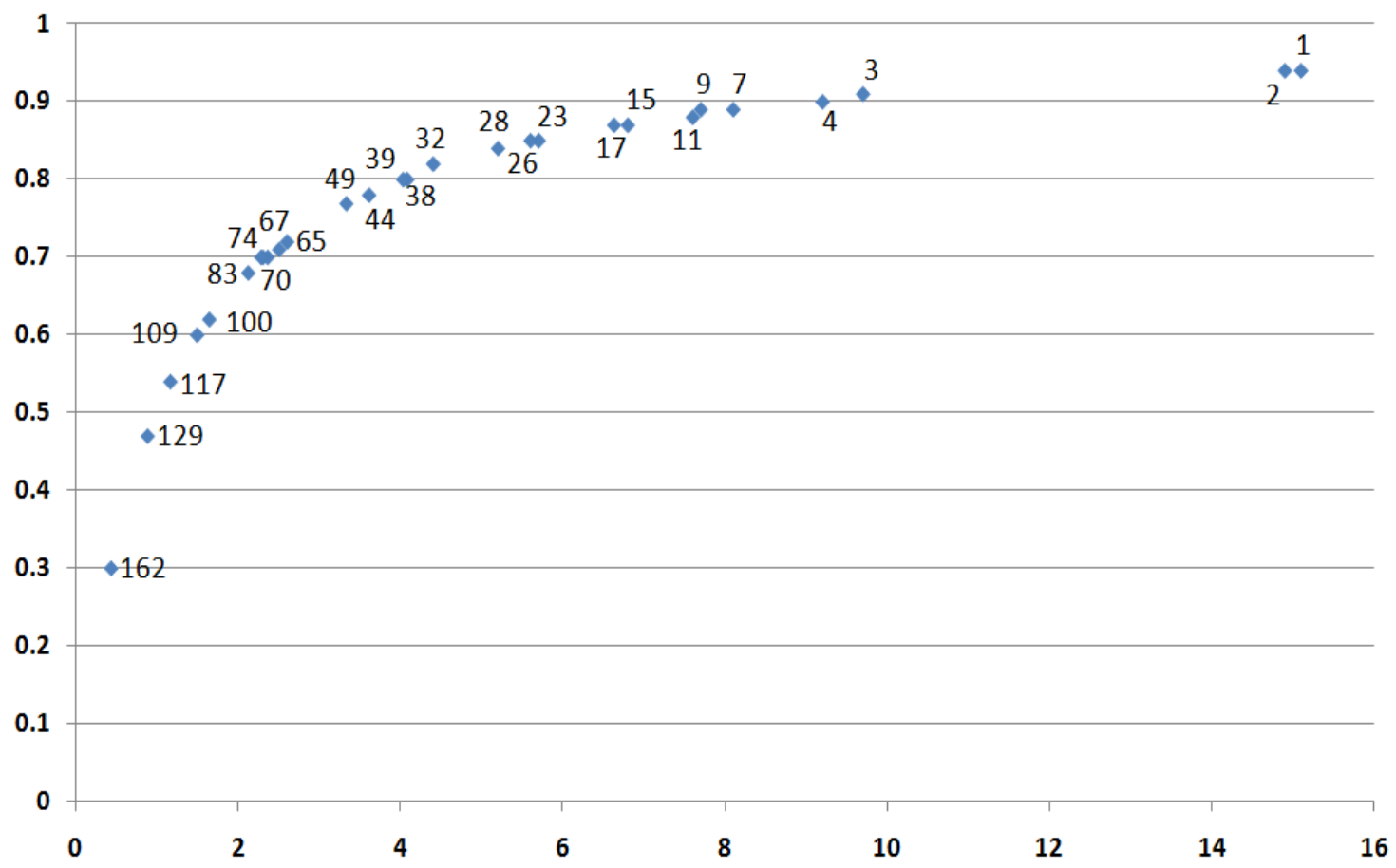

Fig. 1. Dependence of ratings of some countries on quality factor $K$.

The figure shows ratings UN (2010) of countries: Norway (1), Australia (2), New Zealand (3), USA (4), Netherland (7), Sweden (9), Japan (11), Israel (15), Island (17), Italy (23), Great Britain (26), Czech (28), UAE (32), Montenegro (49), RF (65), Kazakhstan (66), Azerbaijan (67), Georgia (74), Turkey (83), Equatorial Guinea (117), Bangladesh (129), Liberia (162).

According to Fig. 1, the development of world states can be divided into three groups:

(1) Developed countries. In this group of countries, the $\mathbf{K}$ factor changes in this range: $5<\mathbf{K}<\infty$. For these states, public interest is much more than personal one.

The value of the HDI (or a) allows you to find out how the state is managed. For example, in the UNDP rating (2016) for the United States $\mathbf{a}=0.92$. This means that $92 \%$ of decisions in the United States are adopted 
by democratic way (D) and only $8 \%$ are administratively (A) adopted. This situation can be written mathematically as: $\mathbf{A}_{\mathbf{0 8}} \mathbf{D}_{\mathbf{9 2}}$.

It is clear from the Fig. 1 that, the value of the HDI is greater than 0.8 in the developed countries. In these countries, decisions (i.e., governance) are adopted basically by the democratic way. But it is impossible to build a full democratic society. Because the value a can approach to the unit (1), but it is impossible to get the value a $=1$ (Khalilov 2014, 321). Khalilov believes that the whole world is intact and its embodiment is unit. Unit can be approached, but it is impossible to reach.

(2) Developing countries. In this group of countries, the $\mathbf{K}$ factor changes in this range: $2<\mathbf{K}<5$. Social and personal interests are protected. In the decision-making process, both totalitarian and democratic methods are used. The $\mathbf{A}_{\mathbf{a}} \mathbf{D}_{1-\mathbf{a}}$ formula can be used to characterize the development of these countries. For example, according to UNDP rating (2016) for Russia, we can write: $\mathbf{A}_{\mathbf{0 . 2 0}} \mathbf{D}_{\mathbf{0 . 8 0}}$. This means that $80 \%$ of the decisions are taken by democratic and $20 \%$ by the administrative methods.

This economathmatical formula for Azerbaijan is: $\mathbf{A}_{\mathbf{0 . 2 5}} \mathbf{D}_{\mathbf{0 . 7 5}}$. So, this means that in Azerbaijan as a developing country, $75 \%$ of the decisions are taken by democratic and $25 \%$ by the administrative methods. The flaws in these countries are related to their thinking. Thus, people with high personal interest are dominant in the management.

(3) Underdeveloped countries. In this group of countries, the $\mathbf{K}$ factor changes in this range: $0.3<\mathbf{K}<2$. For these states, public interest is too smaller than personal one. Total thinking prevails in the management of these countries. In these countries, decisions (i.e., governance) are adopted basically by the administrative methods. For example, in Nigeria $65 \%$ of the decisions are taken by a totalitarian method: $\mathbf{A}_{\mathbf{0 . 6 5}} \mathbf{D}_{\mathbf{0 . 3 5}}$.

From the foregoing, we can conclude that there is a correlation between the HDI and the thinking style. Observations show that as the individual approaches a unit, thinking is enhanced. People can easily share their wealth with those who are in need. B. Gates's family, Tony Hsieh, Dr. Shamsheer Vayalil, and other dozens of people are examples. Tony Hsieh (Hsieh 2011) believes that when he is given some pleasure to others, he feels more satisfied, not only when he gains wealth.

The Table 1 reflects the dynamics of global socio-economic parameters of some countries based on UNDP 2010 and 2016 presentations. Table 1 shows that our planet is a living organism, and global variables vary from country to country during six years. For example, the US has moved from the 4th place to the 8th place in the rankings (column 2), while Belarus has risen from the 61st to 50th place.

Table 1

Macroeconomic Indicators of Some States for 2010 and 2016

\begin{tabular}{|c|c|c|c|c|}
\hline Countries & $\begin{array}{l}\text { UN rating } \\
20102016 \\
\end{array}$ & $\begin{array}{l}\text { HDI = a } \\
20102016\end{array}$ & $\begin{array}{l}\text { K-factor } \\
20102016 \\
\end{array}$ & $\begin{array}{l}\mathbf{A}_{\mathbf{x}} \mathbf{D}_{1-\mathbf{x}} \\
20102016 \\
\end{array}$ \\
\hline 1 & 2 & 3 & 4 & 5 \\
\hline Norway & 1 & $0.938 \quad 0.944$ & $15.1 \quad 16.86$ & $\mathbf{A}_{0.06} \mathbf{D}_{0.94} \quad \mathbf{A}_{0.06} \mathbf{D}_{0.94}$ \\
\hline Australia & 2 & $0.937 \quad 0.935$ & $14.9 \quad 14.38$ & $\mathbf{A}_{0.06} \mathbf{D}_{0.94} \quad \mathbf{A}_{0.06} \mathbf{D}_{0.94}$ \\
\hline Switzerland & 133 & $0.874 \quad 0.930$ & $6.90 \quad 13.29$ & $\begin{array}{lll}\mathbf{A}_{0.23} & \mathbf{D}_{0.87} & \mathbf{A}_{0.07} \mathbf{D}_{0.93}\end{array}$ \\
\hline USA & 4 & $0.902 \quad 0.915$ & $9.20 \quad 10.76$ & $\mathbf{A}_{0.10} \mathbf{D}_{0.90} \quad \mathbf{A}_{0.08} \mathbf{D}_{0.92}$ \\
\hline $\mathrm{RF}$ & $65 \quad 50$ & $0.719 \quad 0.798$ & $2.60 \quad 4.00$ & $\mathbf{A}_{0.281} \mathbf{D}_{0.719} \mathbf{A}_{0.20} \mathbf{D}_{0.80}$ \\
\hline Belarus & 6150 & $0.732 \quad 0.798$ & $2.73 \quad 3.95$ & $\begin{array}{llll}\mathbf{A}_{0.27} & \mathbf{D}_{0.73} & \mathbf{A}_{0.20} & \mathbf{D}_{0.80}\end{array}$ \\
\hline Azerbaijan & $67 \quad 78$ & $0.713 \quad 0.751$ & $2.48 \quad 3.02$ & $\mathbf{A}_{0.29} \mathbf{D}_{0.71} \quad \mathbf{A}_{0.25} \mathbf{D}_{0.75}$ \\
\hline Niger & 167188 & $0.261 \quad 0.348$ & $0.35 \quad 0.53$ & $\mathbf{A}_{0.74} \mathbf{D}_{0.26} \quad \mathbf{A}_{0.65} \mathbf{D}_{0.35}$ \\
\hline
\end{tabular}


Looking at the development of Norway, we see that economic development has changed slightly over the course of six years (columns 3 and 4). This shows that compared to 2010, values for $\mathbf{K}$ have changed slightly (from 15.1 to 16.86) for Norway. This shows that Norway has achieved almost harmonic development.

However, different dynamics are observed in the development of Switzerland. Thus, the development in this country has been noticeable over the past six years, and K's value has risen from 6.9 to 13.3. That is, Switzerland is moving towards harmonic development and the management on $2016\left(\mathbf{A}_{\mathbf{0 . 0 7}} \mathbf{D}_{\mathbf{0 . 9 3}}\right)$ is much more perfect than $2010\left(\mathbf{A}_{\mathbf{0 . 1 3}} \mathbf{D}_{\mathbf{0 . 8 7}}\right)$. As can see from Table 1, factor $\mathbf{K}$ is more sensitive to social and economic changes, than $\mathbf{a}$.

Finally, it can be concluded that totalitarian and democratic methods are used in the management of states. In very poor countries, the classical totalitarian administration is used. In developed countries, mainly democratic governance is used. In developing countries, both administrative and democratic methods are used. These states are developing from totalitarian rule to democratic governance. Therefore, it would be better to call "transitional countries."

\section{Conclusion}

A new criterion for assessing local and global development has been proposed. This criterion shows the ratio of the work (physical or intellectual) which done to path of the work that has not been done. This criterion is more sensitive to social and economic changes. Increasing its value reflects an increase in public interest and a reduction in individual interests.

The annual rating given by the UNDP countries shows that there is a correlation between $\mathbf{K}$ and $\mathbf{a}$ (HDI). As the $\mathbf{K}$ factor increases, the value of $\mathbf{a}$ (HDI) parameter increases with nonlinearity. In this connection, such a law has been established: Humanity develops in the direction of increasing public interest and the history of humanity is the history of public interest.

In order to help human development, the education system should be re-established so that the public interests of the people who go through the education system increase, and their personal decreases.

According to the quality, factor $\mathbf{K}$ states are classified as follows:

(a) Democratic governance. The quality factor for developed countries varies between $5<\mathbf{K}<\infty$. In these states, public interest is much greater than personal interest. These countries are governed by democratic thinking. The socioeconomic indicators of these states are weakly developing depending on the time, but they are stepping forward towards the Supreme Society.

(b) Administrative management. For these states, the value of the $\mathbf{K}$ factor varies in the range of $0.3<\mathbf{K}<$ 2 and $\mathbf{a}(\mathbf{K})$ dependence is strong. The natural totalitarian (classical) method is used in management. Decisions are accepted by totalitarian methods. Public interest is poorly maintained.

(c) Developing countries. For some states, quality factors change in the $2<\mathbf{K}<5$ range. In these countries, both administrative and democratic governance are used. These states are considered developing countries. But it would be better to call the "transitional countries." These states can be mathematically shown in $\mathbf{A}_{\mathbf{1 - a}} \mathbf{D}_{\mathbf{a}}$.

It is believed that there is a link between $\mathbf{K}$ and the thinking style. In very poor countries, the totalitarian administration, in developed countries, mainly democratic governance, in developing countries, both administrative and democratic methods are used.

As the value of $\mathbf{K}$ increases, the humanity is moving towards a happy future. However, it should be taken into consideration that $\mathbf{K}$ may approach infinity, but never $\mathbf{K}=\infty$. Thus, it is impossible to build a full 
democratic and happy society on the native planet, but there is possible to build the qvazi-paradise states on the earth.

\section{Works Cited}

Asgarov, Shahlar Q. "The Impact of Public and Personal Interests on Sustainable Human Development." Proceeing of International Scientific Conference on Sustainable Development Goals. Baku, 24-25 November, 2017. 535-54.

Asgarov, Shahlar Q. “The Philosophy Knowledge Assessment.” Journal of Qafqaz University 13 (2004): 63-72.

Askerov, Shahlar. "A Mathematical Proof of the Existence of God.” The Successes of Modern Natural Science 4 (2011): 165-6. URL: <http://econf.rae.ru/article/5677>.

Askerov, Shahlar, \& Askerov, Анар. “Correlation Between the HDI and GDP.” International Journal of Experimental Education 6 (2012): c. 113-6.

Gamel, Gary. The Future of Management. Brighton, Massachusetts: Harvard Business School Press, 2007.

Human Development Report 2010. "The Real Wealth of Nations: Pathways to Human Development."

Hsieh, Tony. Delivering Happiness: A Path to Profits, Passion, and Purpose. Ed. D. Denisov. Trans. S. Filin. 3rd ed. M.: Mann, Ivanov and Ferber, 2010.

Khalilov, Salahaddin. The Alternative Mathematical Models of the World. Philosophy Study 4.5 (2014): 321.

The Human Development Report 2016. "Human Development for Everyone." 